\section{THE SANGUINARIA CANADENSIS: ITS NATURAL HISTORY, PROPERTIES, AND MEDICAL USES.}

By George D. Gire, M.D., M.A., M.R.C.P, Physician to the St. Pancras Royal Dispensary.

[Real brfore the Hedical Socicty of London, January 23ra, 1860.]

History. The first notice of this plant occurs in Cornuti's Historia Canadensium Plantarum, published in Paris in 1635 being therein described as the Chelidonium maximum Canadense acaulon. In Parkinson's Theatruin Botanicum, published in 1640, an erroneous description of the plant is given, but under the same name as that of Cornuti, and styled the great celandine of Canada. Strange to say, the actual plant itself is very correctly given, with a woodcut, and wrongly named $R a$ nunculus Virginensis albus, the white Virginia crowfoot. From Parkinson's writings, my impression is, that the plant was cultivated in England. Morrison, however, settles the point of its early culture in this country when he states, in his work published in 1680 , that seeds of the plant had been sent to him from Canada and Virginia, which had propagated abun. dantly enough near London. Charlevoix, no mean authority in anything pertaining to Canada, has adopted the same name as that given by Cornuti, in his Histoire de la Nouvelle France; and moreover styles it the dragon's blood of Canada, "sang dragon du Canada". The most correct and accurate account of it, however, is to be found in the Hortus Elthamentus of Dillenius, in which several figures of the plant are given, coloured most naturally, under the name of Sanguinaria major et minor. Linnæus finally settled the name by adding Canadensis to its appellation of Sanguinaria, thus embodying its great peculiarity and first known habitation. It is described in many American works on botany, but comparatively in few English. The first introduction of this plant into Europe was through the return to France of some of the earlier travellers in Canarla, where the plant was first seen. It was cultivated in the gardens of Paris, and this enabled Cornuti to describe it in 1635 ; and there can be no doubt whatever that that writer never was in Canada.

I cannot conclude this short account of the early history of the blood-root without reference to an author for whose writings I entertain very great respect. This is a little work by Mons. Pierre Boucher (published at Paris in 1664), who was Governor of 'Three Rivers, in Canada. He is the first author who says anything about many of the plants of Canada, from observation on the spot; and I have no doubt that he refers to the sanguinaria in speaking of " une espèce de lys", at page 86 . Charlevoix, however, is the first writer who refers to the use made of the plant; he uses the expression, "C'est souvent servi de la racine de cette plante pour provoquer les mois": in other words, it was employed as an emmenagogue.

Botanical Characters. The plant belongs to the sexual system Polyandria Monogynia, and the natural order Papa. veraceæ. Its chief peculiarities are, a little white flower, with usually eight petals; a lobed leaf, veined on the under side with orange; and an abrupt, horizontal, often contorted rhizome, about as thick as the little finger, two to four inches long. It flowers in April and May, as soon as the frost and snow leave the ground. The leaves continue to grow long after inflorescence, and attain to a large size, with numerous lobes.

It has various names, but puccoon is the familar Indian appellation. Dillenius speaks of it a hundred and thirty years ago, under this name, which was derived from the Indians, "pocan Indigenis dici". It is also called red root, red puccoon, and Indian paint. Canada is essentially the country of the blood-root; I have seen it growing in various parts of that division of the British Empire. It is found as far eastward as Labrador, and to the north of the Saskatchevan, on the eastern side of the Rocky Mountains. It spreads south, and is found in all the States of the American Union, living in various kinds of soils, derived from various geological formations, and to some extent varying in the delicacy and appearance of its leaves. The root everywhere seems to be the same. It has not been found in a fossil state, although I am strongly impressed with the belief that it flourished anterior to the last deposition of the tertiary strata; but, from the perishable nature of its materials, no relics have been left behind.

The Rhizome: Physical Properties. The only officinal part of this hardy little herbaceous perennial plant is the rhizome or root. When fresh, it is from two to three and a half and four inches long, abrupt at the end, often contorted and truncated, about as thick as the finger, fleshy, round, being for the most part tolerably stout in the middle, with a curvature at each end, covered with orange fibres two or more inches long, of a reddish brown colour externally, inclining to copper, of $\varepsilon$ brighter blood-red within, and abounding in an orange-colourea juice, which escapes when it is cut. When dried, the root has considerably shrunken, and, as met with in commerce, is in pieces from one to three inches long, flattened, heavy, much wrinkled and twisted. The surface of a fractured portion is at first bright orange. There is but one kind only of the bloodroot employed in commerce, and it is met with unadulterated, there being no inducement to practise fraud, from its cheapness and abundant growth. Two packages of the dried root, sent me by my friend Dr. Fenwick, obtained from Lyman, Savage, and Co., druggists, of Montreal, contained eight pounds each, and were put up in oblong deal boxes, with a sliding lia, and were perfectly air-tight.

The odour of the root is peculiar and somewhat narcotic, and, on handling it, causes sneezing. The taste is bitterish, acrid, and durable. The sneezing effect is also produced by stirring the powder. It yields its virtues to water and alcohol, and these are the greatest when the seeds are ripe, in May and July. The powdered root possesses a brighter brownish orange-red colour than powaered cinnamon, and otherwise re sembles it. The seeds are the size of grains of barley, dark shiny reddish brown, half surrounded with a peculiar white vermiform appendage. Like most of the seeds of the poppy tribe, the albumen is between fleshy and oily. The juice of the plant, generally of an orange colour, sometimes assumes the tint and redness of blood, especially in the northern parts of Canada. A horizontal section of the fresh root is one of the most beautiful objects in nature under the microscope.

Chemical Characters. All parts of the plant have been sub. mitted to chemical analysis by myself and several other observers; but no regular table of qualitative analysis has been submitted to the profession before that now brought forward by myself on the present occasion. It contains-l. Sanguinarina 2. Porphyroxin ; 3. Puccine; 4. Chelidonic acid; 5. Feculi: 6 . Saccharine matter; 7. Vegetable albumen; 8 . Orange-coloured resin; 9. Fixed oil; 10. Extractive matter; 11. Lignin; 1 ? Gum.

The sanguinarina was first discovered by Dr. Dana of New York in the root, and is the active principle of the plant; it is an acrid white substance, which forms coloured salts with the acids. I have detected it in the leaves, and have no doubt it is present in the seeds. It is obtained by Dana's, Schiel's, and Probst's different processes, which are to be given elsewhere. Its formula, according to Schiel, is $-\mathrm{C}^{37}, \mathrm{H}^{32}, \mathrm{~N}^{2}, \mathrm{O}^{8}$.

The sulphate I show was obtained in the preparation of the alkaloid by Schiel's process.

Porphyroxin was extracted from the root by Riegel, and is precisely analogous to the same principle discovered by Merck in opium; and this has induced me to adopt the same name for it in the sanguinaria.

Puccine is a third distinct principle, discovered by $\mathrm{Mr}$. Edward S. Wayne of Cincinnati, in the ether after the precipitation of the sulphate of sanguinarina, in the process of Schiel As it has not heen named, $\bar{I}$ have ventured to call it puccine, deriving that appellation from the Indian name of the plant. The quantity is so small, that fifteen pounds of the root yielded but 130 grains of it.

Chelidonic Acid has been obtained from the root by $\mathrm{Mr}$. Wayne, who considers the acrid and pungent taste it possesses as due entirely to a salt of sanguinarina, probably the chelidonate. The sanguinarina and puccine would appear to have but little taste.

Fecula I myself detected by precipitation with alcohol from a cooled infusion of the root. After twenty-four hours, the examination of the subsided flocculi with the microscope showed numbers of clear, thin, and transparent starch-granules, mostly circular, with an occasional hilum. A drop or two of iodine gave the characteristic blue colour.

Saccharine Matter I discovered by applying the usual tests for sugar, especially Barreswil's solution.

Vegetable Albumen in small quantity I found in the root, and a large amount in the seeds.

Fixed Oil I obtained in the form of a yellowish liquid, soluble in ether.

Extractive Matter, Lignin, and Gum, are also found.

Physiological Effects. I have performed various experiments upon plants and animals, to study its physiological effects; and so has my friend Dr. Fenwick of Montreal. His were chiefly upon dogs and cats. He found large doses to act as an irritant poison, causing frothing at the moutb, vomiting, and purging. 
In two dogs, the matter ejected from the stomach, as well as that passed by stool, was mixed with blood. The circulation at first fell, and then rose; there was great thirst, the animal constantly lapping water; the ocular conjunctivæ became suffused, pupils dilated, vision impaired; slight convulsions set in, then coma, stertor, and death in two hours. A drachm of the powder killed a young cat in four hours, with these symptoms. Two drachms were fatal, about the same period, to a full grown cat; and four drachms given to a dog were fatal within two hours. Dissection revealed patches of injection and redness of the mucous membrane of the stomach and bowels, with softening, as this membrane could very readily be peeled off. In its concentrated form, it seems extensively irritating to the mucous membrane generally, whether in man or in animals.

On man, in small doses, it excites the stomach, accelerates the circulation, and acts as an agreeable cerebral excitant; it stimulates the secretions, especially those of the entire bronchial mucous membrane, and also, as has been asserted, those of the liver. If more largely given, it produces nausea; and if its action is kept up continuously, or repeated at intervals, it lessens the frequency of the pulse in a manner somewhat analogous to the operation of digitalis. In a full dose, it occasions vomiting. This is from ten to twenty grains, and is its most striking effect, accompanied with a sense of heat, or sometimes a burning sensation in the fauces. An excessive quantity or an over-dose of the root acts as a poison, and produces violent vomiting, a burning sensation of the stomach, tormenting thirst, faintness, vertigo, indistinct vision, and alarming prostration of strength. The romiting may not be immediate, and nausea may continue for some time, until it does ensue. It irritates the fauces, leaving an impression in the throat for a considerable time after it is swallowed. In July 18t1, four persons lost their lives at the Bellevue Hospital, New York. They were employed in whitewashing the apothecary's shop; and each of them drank out of a demijohn left there a large quantity of the tincture of blood-root, which they mistook for intoxicating liquor. They were all soon seized with racking and burning pains, and a tormenting thirst; and all died during the ensuing day. The effects, therefore, of an overdose are those of a violent acrid narcotic; and, although no mention is made of any post mortem examination, it may reasorably be assumed that violent inflammation had ensued of the stomach and bowels. I might add much more in the way of experiment, and the influence of the seeds and the leaves on the economy; but sufficient has been stated to give a clear idea of the physiological effects of the plant.

Therapeutic Action. In relation to its action, sanguinaria possesses emetic, nauseant, expectorant, diaphoretic, narcotic, sedative, stimulant, and alterative properties. It acts, also, as an emmenagogue, escharotic, and errhine. Occasionally, it exerts a diuretic, purgative, anthelmintic, and antipsoraic effect. It is said to be prophylactic. All these are regulated by the dose and form in which it is administered; it is, however, chiefly valuable for its emetic and expectorant powers, and its action as an emmenagogue.

1. As an emetic, nauseant, and expectorant, it is highly valuable in various chest and throat affections, and has been employed in pneumonia, phthisis, bronchitis, catarrh, asthma, croup, diphtheria, cynanche maligna, and pertussis. It is less used as an emetic than as a nauseant, expectorant, and alteratine. It is not followed by the depression of other emetics, but rather supports and stimulates. In this way, it is valuable in croup, being pronounced a specific by some writers. In the croupal and malignant forms of diphtheria it will be found not less serviceable. In Germany and other parts of the Continent it is used as an emetic. Its expectorant and stimulant properties are easily exerted. It should not be used during high febrile excitement, nor acute inflammatory affections, until after depletion. It forms the chief ingredient of Ayer's cherry pectoral, combined with antimony, ipecacuan, morphia, and syrup of cherry-tree bark.

2. As a diaphoretic, narcotic, sedative, stimulant, and alterative, it is employed in scarlatina, rheumatism, jaundice, dyspepsia, hydrothorax, and some other affections. These effects are produced by small and repeated doses. As a gargle it is employed in scarlatina. Combined with opium, it is said to be one of the best and safest diaphoretics. Its narcotic action follows the primary stimulation of the heart's action. As an anodyne per se it is not worthy of trial, but its sedative effect upon the heart is very certain, after its first excitement disappears; the pulse then gradually decreases in frequency. Two to four grains of the powder, every hour, will produce a sedative action.
3. As an emmenagogue, it deserves some consideration, and has long been known to exert its virtues in this way. I have proved its value by experience, and have found that when it is taken freely, it has produced, in some instances, menorrhagia; in others, again, it has cured leucorrhœa. The North American Indians believe in its occasioning nymphomania, and their love powders are composed of sanguinaria. I am satisfied that it does exert some influence on the uterine system, and it will prove emmenagogue when other substances fail to do so. In the report of the Surgical Staff of the Middlesex Hospital, published in 1857, is the following quotation:- " It is evidently a powerful remedy, and as an emmenagogue is, perhaps, equal to any drug now employed in England."

4. As an escharotic, it irritates the surface of ulcers, promotes absorption of exuberant granulations, and changes action; it also exerts an effect on diseases of the skin. It cleanses wounds or ill-conditioned ulcers by its stimulant properties. As for its asserted value in promoting the disappearance of tumours and the cure of cancers, there is not the slightest evidence to favour such a view, and American surgeons were astonished when it was propounded, as experience in their hands had proved it to be utterly useless in that respect. This is stated on the authority of most of the respectable medical journals in the United States and in Canada. Moreover, the assertion that it was in use among the Indians on the shores of Lake Superior, as a remedy to cure cancer, is utterly gratuitous and assumptive. It has never been employed for such a purpose by them, and this is stated, in the most positive manner, on the best authority, and without the least fear of contradiction. The profession in this country have formed a correct estimate of its value in cancer ; it is perfectly inert in that disease.

5 . As an errhine, it has been used in coryza, and in cases of polypus of the nose.

6 . As a diuretic and purgative, there is very little evidence to prove it to be either. Dr. Fernwick, of Montreal, and some others, have asserted that the squaws employ it as as anthelmintic. And, as a prophylactic, it is used against the invasion of intermittent fevers.

$$
\text { [To be continued.] }
$$

Preservation of Leeches. Hospitals and vendors have endeavoured to derive advantage from leeches by making them serve several times, and especially by preserving them, by con veying them without danger, etc. Numerous apparatuses have been invented with this view, but M. de Quatrefages has espetially brought under the notice of the Academy of Sciences, that of M. Vayson, an eminent breeder commissioned by the administration to study the breeding of leeches in Algeria. This apparatus, which its author denominates a domestic marsh, consists simply of an earthenware vessel in the form of a truncated cone reversed, the lower extremity of which is pierced with a few holes, sufficiently narrow not to allow the leech to pass through. This vessel is filled with turfy earth; the leeches are placed in it, and they soon install themselves as well as they can; then the orifice of the vessel is closed with a coarse cloth. If they have to be forwarded to a great distance the earth is wetted in all its thickness and the vessel is packed in a case, or merely a basket. If the leeches have to be preserved on the same spot, the lower end of the vessel is placed in a tub, the water of which rises to about the height of four inches, and no further care is required. By the process of infiltration the lower strata of the little marsh are soon wet through, the upper strata remaining almost dry. Between these two extremes the leeches know perfectly well how to choose the zone most appropriate for them, and deep galleries in which they live as it were en famille. The leeches transported from the Bordelais to Algeria, those brought from Algiers to Paris, had been shut up in these domestic marshes. The former occupied to the number of nine hundred, two of these apparatuses. Not one had died on the way up to the arrival at Algiers. The others, to the number of a thousand, were, on their arrival, in the most satisfactory state. But it is not merely as a means of conveyance that these apparatuses have been praved to be useful; they are not less so as reservoirs intended for the preservation of leeches. In several Parisian hospital, leeches that have been already used are employed again; but, after being used five times consecutively, they die off in the space of a few weeks. But these same leeches that had been exhausted, when placed in M. Vayson's apparatus, have been tolerably well preserved, and at the end of two months a third of them was left. (Journal de Médecine et de Chirurgie pratiques.) 